\title{
Special issue: multiscale technologies for irrigation management
}

\author{
S. Ortega-Farias ${ }^{1}$. D. S. Intrigliolo ${ }^{2}$
}

Published online: 7 January 2021

(c) The Author(s), under exclusive licence to Springer-Verlag GmbH, DE part of Springer Nature 2021

Water resources for irrigation have been decreased in the main agricultural areas around the world due to frequent droughts and increasing demand for water use among agriculture, industry, and urban areas. For water-scarcity scenarios, irrigation management strategies such as sustainable (SDI) and regulated (RDI) deficit irrigation have been suggested for improving water productivity (production per unit of consumed water, $\mathrm{kg} \mathrm{m}^{-3}$ ) and optimizing the yield and quality of crops, orchards, and vineyards, especially in Mediterranean climate regions (Chai et al. 2016; Fereres et al. 2014; Gómez-del-Campo 2013; Romero et al. 2015). The monitoring of actual evapotranspiration (ET), soil water content (SWC), and plant water status $(\Psi)$ has been used as a decision-making tool for scheduling water applications in the SDI and RDI strategies. Traditionally, ET is estimated using the reference evapotranspiration (ETo), which is multiplied by a single $(\mathrm{Kc})$ or dual $(\mathrm{Kd})$ crop coefficient. However, the $\mathrm{Kc}$ and $\mathrm{Kd}$ values suggested in the literature require local calibration because they depend on non-linear interactions among soil, cultivar, climate, and agricultural management (Cammalleri et al. 2013). ET modeling and local development of $\mathrm{Kc}$ and $\mathrm{Kd}$ have been performed using different ground-based techniques such as lysimeter, soil water balance (SWB), eddy covariance (EC) system, Bowen ratio (BR) method, scintillometer, and sap flow (SF) sensors (Paul et al. 2014). While crop coefficient values have been established for several crops (Pereira et al. 2021), there are still gaps in our current knowledge, particularly for the less

S. Ortega-Farias

sortega@utalca.cl

1 Research and Extension Center for Irrigation and Agroclimatology (CITRA), Research Program On Adaptation of Agriculture To Climate Change (A2C2), Faculty of Agricultural Sciences, Universidad de Talca, Campus Talca, Chile

2 Centro de Edafología y Biología Aplicada del Segura (CEBAS), Consejo Superior de Investigaciones Científicas (CSIC), 30100 Murcia, Espinardo, Spain widespread crops and particularly those more often grown in humid areas.

To reduce the uncertainty associated with the $\mathrm{Kc}$ and $\mathrm{Kd}$ values, measurements of SWC have been recommended, to schedule irrigation of horticultural crops. The main limitation is that SWC measurements do not represent water use in crops with extensive root systems, mainly growing in deep soil (Dobriyal et al. 2012). Besides, SWC sensors do not accurately predict the SWC in soil with high salinity and a high stone percentage. As an alternative to SWC sensors, recent reports suggested that hydrogeophysical methods such as electrical resistivity tomography (ERT) or electrical resistivity imaging (ERI) can image the dynamics and spatial distribution of the SWC (Bertermann and Schwarz 2018; Cassiani et al. 2015).

From a physiological point of view, $\Psi$ measurements better integrate the effect of soil, plant vegetative vigor, and climate on water requirements compared with SWC measurements (Granier et al. 2006). The predawn $\left(\Psi_{\mathrm{PD}}\right)$, midday leaf $\left(\Psi_{\mathrm{L}}\right)$, and midday stem $\left(\Psi_{\mathrm{MD}}\right)$ water potentials are a good predictor of plant water status and have been proposed as reliable techniques for irrigation management of crops, orchards, and vineyards under SDI and RDI strategies (Naor 2006). However, the measurements of $\Psi_{\mathrm{PD}}, \Psi_{\mathrm{L}}$, and $\Psi_{\mathrm{MD}}$ are carried out in the field for each plant and expensive to collect a reasonable amount of data.

It is relevant to point out that ground-based measurements of ET, $\Psi$, and SWC do not consider the effect of the intra-field spatial variability in the canopy size, soil characteristic, and salinity on irrigation scheduling. This issue is crucial in orchards and vineyards that generally present heterogeneous canopy structures due to training systems, which result in different canopy sizes, leaf area indices, plant densities, and fractional covers (López-Olivari et al. 2016). Remote sensing (RS) techniques combined with groundbased climate data can characterize the effect of intra- and inter-field spatial variability of canopy size and soil characteristics on the estimation of ET (Jin et al. 2018; Kustas et al. 2019). The potential use of three and two-source models has recently been evaluated to compute the intra-orchard spatial 
variability of ET using thermal infrared (TIR) and multispectral sensors placed on satellite and unmanned aerial vehicle (UAV) platforms (Hoffmann et al. 2016). The use of these platforms will depend on the spatial and temporal resolution that is required for irrigation management. The satellite can be applied at a regional-scale, and UAV can be used to evaluate the intra-field variability.

This Special Issue includes eight papers about on-theground measurement techniques and remote sensing tools for improving water management of orchards, vineyards, and crops. Four papers indicate the ET modeling using multiscale techniques such as the Bowen ratio, eddy correlation, scintillometry, surface renewal, satellite images, and thermal infrared camera placed on UAV (Elfarkh et al.; Marino et al.; Pinho Sousa et al.; Riveros-Burgos et al.). Two papers evaluate technologies for monitoring physiological plant responses to water stress, such as plant water status, lysimeters, and SWC sensor (Colak et al.; Wu et al.). Finally, two papers describe hydrogeophysical techniques (ERT and ERI) for characterizing the dynamics and meter-scale soil water heterogeneity (Araya-Vargas et al.; Vanella et al.).

In this issue, de Pinho Sousa et al. report the estimation of ET, Kc, and Kd using the BR system for irrigated acai palm grown in the Eastern Amazon, Brazil. This study fully characterizes water consumption during the growing seasons providing seminal information to improve irrigation efficiency in acai palm, ensuring a more sustainable water use. On the other hand, in general, for all crops, the information available about crop water use values under suboptimal conditions (i.e., water quantity or quality restrictions) is still scarce. To cover this research gap, in this issue, Marino et al. quantified Pistachio tree water use reductions due to salinity and sodicity and also the physiological drivers for the observed changes in the energy balance components due to salinity. This type of research is nowadays required to be able to better scheduled irrigation under certain restrictions in water quality, which are every time more frequent as a consequence of the increased pressure for water resources.

At the regional scale, the estimation of ET is needed as the main component for the water-energy balance in complex and heterogeneous surfaces. In this issue, Elfarkh et al. integrate thermal stress indexes within Shuttleworth-Wallace model for ET mapping over a heterogeneous semi-arid region. To calculate ET, this study combines satellite images such as those from the Landsat series, including information from the thermal spectral region. At the plot level, advances for ET determinations are arising from the use of TIR cameras on board the UAV. In this issue, RiveroBurgos et al. evaluate the clumped model for estimating the intra-orchard spatial variability of ET of drip-irrigated olive trees using meteorological data and high-resolution TIR imagery acquired by a UAV. This resulted in determining the whole plot water use requirements, but also to characterize the variation of water use within the orchard as a first step to further develop precision irrigation scheduling. In the future, the challenge is to deliver different watering regimes according to the ET variation previously mapped using, for instance, the methodology based on the work by Rivero-Burgos published in this issue.

Mapping evapotranspiration at high spatial resolution also has the advantage of potentially separately quantifying soil evaporation from plant transpiration, which is a requisite when for instance, using subsurface drip irrigation for water savings, such as in the research presented in this issue by Colak et al. Higher efficiency in water use can be also achieved when RDI is applied as in the case of the Quinoa crop where results shown by Colak et al. have determined threshold values for $\Psi_{\mathrm{L}}$ to optimize deficit irrigation application for the Quinoa crop. The final application of these types of results by irrigators will require the on-field determination of plant water status, which is time-consuming and difficult to be carried out at the commercial level. To overcome this limitation, models could be employed to predict plant water status and transpiration under certain soil water deficit situations. The enormous advancements made in the last year in terms of digitalization and data analysis are resulting in the widespread use of decision support systems. However, to implement these digital tools, more knowledge is required for predicting plant physiological responses to water restrictions. In this issue, Wu et al. obtained new findings to parametrize better root water uptake and plant transpiration under variable levels of water deficit, facilitating the development of new crop models to simulate better plant responses to water stress.

This Special Issue is also finally considering new development in terms of SWC monitoring. This information is particularly required when localized irrigation is applied complementing ET estimates to better determine the frequency of irrigation applications. In addition, even if drip irrigation is already a well-established state-of-the-art technology for optimizing in-field irrigation applications, the required dimension of the wet bulbs needs to be correctly determined to avoid detrimental restrictions in root water uptake. In this Special Issue, Araya-Vargas et al. report the usefulness of the ERT technologies by comparing ERT results with independent determinations of the vineyard soil water balance. On the other hand, the ERI technique was evaluated by Vanella et al. in a citrus orchard to characterize the soil wetting patterns and the size of the wet bulbs as crucial aspects for modeling soil evaporation and improve the drip irrigation agronomic design.

Irrigated agriculture faces the challenge of ensuring the continuous supply of food and feed for a growing population without compromising the natural resources available, namely land and water. A sustainable intensification process is, therefore, required which is only possible by searching 
for additional agronomic and engineering solutions to keep improving water productivity and by better implementing at the different scales the solutions already tested at a researchlevel such as those described in this Special Issue. The challenge is also to integrate at a large scale, the potential solutions, which require that the water governance aspects are considered either by better adapting current local regulations or tailoring the possible technologies to the existing water allocation mechanisms already in place.

\section{References}

Bertermann D, Schwarz H (2018) Bulk density and water content dependent electrical resistivity analyses of different soil classes on a laboratory scale. Environ Earth Sci 77(16):570

Cammalleri C, Ciraolo G, Minacapilli M, Rallo G (2013) Evapotranspiration from an olive orchard using remote sensing-based dual crop coefficient approach. Water ResourManag 27:4877-4895. https://doi.org/10.1007/s11269-013-0444-7

Cassiani G, Boaga J, Vanella D, Perri MT, Consoli S (2015) Monitoring and modelling of soil-plant interactions: the joint use of ERT, sap flow and eddy covariance data to characterize the volume of an orange tree root zone. Hydrol Earth SystSci 19(5):2213-2225. https://doi.org/10.5194/hess-19-2213-2015

Chai Q, Gan Y, Zhao C, Xu HL, Waskom RM, Niu Y, Siddique KHM (2016) Regulated deficit irrigation for crop production under drought stress A review. Agron Sustain Dev 36:3

Dobriyal P, Qureshi A, Badola R, Hussain SA (2012) A review of the methods available for estimating soil moisture and its implications for water resource management. J Hydrol 458:110-117

Fereres E, Orgaz F, Gonzalez-Dugo V, Testi L, Villalobos FJ (2014) Balancing crop yield and water productivity tradeoffs in herbaceous and woody crops. Funct Plant Biol 41:1009-1018. https:// doi.org/10.1071/FP14042

Gómez Del Campo M, García JM (2013) Summer deficit-irrigation strategies in a hedgerow olive cv. arbequina orchard: effect on oil quality. Irrig Sci 31:259-269
Granier C, Aguirrezabal L, Chenu K, Cookson SJ, Dauzat M, Hamard P, Thioux JJ, Rolland G, Bouchier-Combaud S, Lebaudy A (2006) PHENOPSIS an automated platform for reproducible phenotyping of plant responses to soil water deficit in arabidopsis thaliana permitted the identification of an accession with low sensitivity to soil water deficit. New Phytol 169:623-635

Hoffmann H, Nieto H, Jensen R, Guzinski R, Zarco-Tejada P, Friborg T (2016) Estimating evaporation with thermal UAV data and twosource energy balance models. Hydrol Earth Syst Sci 20:697-713. https://doi.org/10.5194/hess-20-697-2016

Jin Y, He R, Marino G, Whiting M, Kent E, Sanden BL, Culumber M, Ferguson L, Little C, Grattan S, Paw UKT, Lagos LO, Snyder RL, Zaccaria D (2018) Spatially variable evapotranspiration over salt affected pistachio orchards analyzed with satellite remote sensing estimates. Agric For Meteorol 262:178-191. https://doi. org/10.1016/j.agrformet.2018.07.004

Kustas WP, Alfieri JG, Nieto H, Wilson TG, Gao F, Anderson MC (2019) Utility of the two-source energy balance (TSEB) model in vine and interrow flux partitioning over the growing season. Irrig Sci 37:375. https://doi.org/10.1007/s00271-018-0586-8

Naor A (2006) Irrigation scheduling and evaluation of tree water status in deciduous orchards. Hortic Rev 32:111-163

Pereira LS, Paredes P, Hunsaker DJ, López-Urrea R, MohammadiShad Z (2021) Standard single and basal crop coefficients for field crops. Updates and advances to the FAO56 crop water requirements method. Agricultural Water Managt 243:106466. https:// doi.org/10.1016/j.agwat.2020.106466

Romero P, Muñoz RG, Fernández-Fernández JI, del Amor FM, Martínez-Cutillas A, García-García J (2015) Improvement of yield and grape and wine composition in field-grown Monastrell grapevines by partial root zone irrigation, in comparison with regulated deficit irrigation. Agric Water Managt 149:55-73. https:// doi.org/10.1016/j.agwat.2014.10.018

Publisher's Note Springer Nature remains neutral with regard to jurisdictional claims in published maps and institutional affiliations. 